\title{
From in-silico immunogenicity verification to in vitro expression of recombinant Core-NS3 fusion protein of $\mathrm{HCV}$
}

\author{
Hekmat $\mathrm{S}^{1,2}$, Siadat $\mathrm{SD}^{2,3}$, Aghasadeghi $\mathrm{MR}^{1}$, Sadat $\mathrm{SM}^{1}$, Bahramali $\mathrm{G}^{1}$, Aslani $\mathrm{MM}^{2,5}$, \\ Mahdavi $\mathrm{M}^{4}$, Shahbazi $\mathrm{S}^{1}$
}

Department of Hepatitis and AIDS, Pasteur Institute of Iran, Tehran, Iran. sh_hekmat@yahoo.com

\begin{abstract}
BACKGROUND AND OBJECTIVE: Hepatitis C virus (HCV) is a serious global health burden. There is no effective vaccine against HCV and new direct acting antivirals (DAAs) are so expensive and virtually unavailable to the public. Therefore, seeking for therapeutic or prophylactic vaccines is exigent and reliever.

METHODS: The secondary and tertiary structures of the recombinant Core-NS3 ( $\mathrm{rC}-\mathrm{N}$ ) fusion protein of HCV and its $\mathrm{B}$ and T-cells epitopes were evaluated with bioinformatics software. Cloning and in vitro expression of $\mathrm{rC}-\mathrm{N}$ were performed by $\mathrm{pET} 24 \mathrm{a}(+)$ and E.coli BL21-DE3 expression host, respectively. The recombinant protein purification was done by affinity chromatography method and then identified by Western blotting using anti-His monoclonal antibody.

RESULTS: The sequences of rC-N protein consist of 1-118 amino acid parts of Core and 1095-1384 amino acids of NS3 were connected by a flexible linker (AAY) with proteasome cleavable site. The expressed and purified $46.7292 \mathrm{kDa}$ rC-N protein had antigenic value up to threshold and conservancy found in this chimeric protein. Ramchandran Plot analysis represented that most residues were fallen in favourable regions. It also interacted with both type I and II major histocompatibility complex ( $\mathrm{MHC} \mathrm{I}$, II) molecules. The rC-N had antigenic behaviour to create $T$ cell responses.

CONCLUSION: The results indicated that conserved $\mathrm{rC}-\mathrm{N}$ protein had the ability to induce T-cell-mediated immune responses and it could be utilized as a therapeutic vaccine candidate against HCV (Tab. 3, Fig. 4, Ref. 40). Text in PDF www.elis.sk.

KEY WORDS: HCV vaccine, fusion protein, Core, NS3.
\end{abstract}

\section{Introduction}

Hepatitis $\mathrm{C}$ virus (HCV) infection remains a leading cause of liver cirrhosis, hepatocellular carcinoma and lymphomas. The recent estimations showed approximately 185 million people, who are infected with this virus, $73 \%$ of them live in middle-income countries $(1,2)$. However, new direct acting antivirals are over 95-99 \% effective against chronic HCV genotype 1 and 2, but they are so expensive (about 63-300000 US \$, per a period of treat-

${ }^{1}$ Department of Hepatitis and AIDS, Pasteur Institute of Iran, Tehran, Iran, ${ }^{2}$ Microbiology Research Centre (MRC) Pasteur Institute of Iran, Tehran, Iran, ${ }^{3}$ Department of Mycobacteriology and Pulmonary Research, Pasteur Institute of Iran, Tehran, Iran, ${ }^{4}$ Department of Immunology, Pasteur Institute of Iran, Tehran, Iran, and ${ }^{5}$ Department of Microbiology, Pasteur Institute of Iran, Tehran, Iran.

Address for correspondence: S.D. Siadat, PhD, Department of Mycobacteriology and Pulmonary Research, Pasteur Institute of Iran, Microbiology Research Centre (MRC) Pasteur Institute of Iran, No. 69, 12th Farwardin Ave, Tehran, 1316943551 Iran.

Phone: +982166969291, Fax: +982166969291

Acknowledgement: We gratefully acknowledge hepatitis \& AIDS and mycobacteriology departments experts for their advises and technical supports. S. Hekmat was supported by Education office of Pasteur Institute of Iran to pursue her study in the Ph.D. program. ment, with or without cirrhosis) and inaccessible for all patients, especially for those, who live in low and middle income countries. Therefore, seeking for new drugs and therapeutic or anaphylactic vaccines is exigent $(3,4)$.

The size of positive sense single stranded RNA genome of $\mathrm{HCV}$ is about $9.6 \mathrm{~kb}$ and encodes a large poly protein of 3010 to 3033 amino acid residues. The proteins of HCV are arranged along the genome in the following order: $\mathrm{N}$ terminal-core-envelope proteins (E1-E2)-p7-nonstructural proteins (NS)-NS2-NS3-NS4ANS4B-NS5A-NS5B-C terminal $(5,6)$.

The core protein with 191 amino acids can be divided into three domains on the basis of hydrophobicity: domain 1 (amino acids 1-117), which contains mainly basic residues with two short hydrophobic regions; domain 2 (amino acids 118-174), which is less basic and more hydrophobic and its C-terminus is at the end of 21 ; domain 3 (residues 175-191), which is highly hydrophobic and acts as a signal sequence for E1 envelope protein (7-9). The sequences of core are the most conserved parts of the hepatitis $\mathrm{C}$ genome and have many B cell and T cell epitopes (10).

Non-structural protein 3 contains a serine protease and an RNA helicase. Protease cleaves the genome-encoded polyprotein and inactivates cellular proteins required for innate immunity. Helicase is required for both genome replication and virus assembly. Special characteristics and relatively preserved structure of NS3 makes it 


\section{9-195}

a suitable target for the development of antiviral therapeutics and vaccine research $(7,8,11)$.

Synthetic fusion protein base vaccines are more advanced and applicable in comparison with traditional vaccines. They not only provide opportunities for specific purposes, but also can make ability to exclude deleterious sequences from full-length genome. Also, synthetic protein base vaccines are safer than attenuated or inactivated vaccines. Likewise, HCV culture is difficult and it can be an essential obstacle to traditional vaccine development $(12,13)$.

The CD4+ and CD8+ T cells immune responses are essential for an effective campaign after infection by hepatitis $C$ virus (14, 15). T cell adoptive transfer therapy or prophylactic vaccine based on Core and NS3 proteins is suitable to induce both $\mathrm{CD} 4+$ and CD8+ $\mathrm{T}$ cell responses against HCV (16-17).

\section{Objectives}

The present study aimed to immunoinformatic analysis, modelling and simulation of conserved and immunogenic regions in core and NS3 genes from HCV 1a genotype by using online bioinformatics tools, thereafter, expression and purification of this projected construct to produce recombinant Core-NS3 (rC-N) fusion protein for its potential application as therapeutic vaccine candidate. By the next considerations, the chimeric produced protein will be evaluated solitarily or besides some adjuvants in the future.

\section{Materials and methods}

Sequence analysis of recombinant Core, NS3 fusion protein (rCN)

In order to do in-silico translation of a hepatitis $\mathrm{C}$ recombinant fusion protein to obtain amino acid sequences in high levels of CTL epitopes, some parts of core and ns 3 gene sequences, corresponding to genotype 1a were derived from the national centre of biotechnology information (hhtp://www.ncbi.nlm.nih.gov). These two peptides were analysed for conserved domains in (NCBIConserved Domains) http://www.ncbi.nlm.nih.gov/Structure/cdd/ cddsrv.cgi?uid=111760.

Physicochemical properties of both fragments were computed using ProtParam online tool (http://web.expasy.org/protparam/) (18), while a flexible linker with proteasome cleavable site was predicted by Rankpep (http://bio.dfci.harvard.edu/RANKPEP) and paproc (http://paproc.de) to obtain final rC-N sequence.

Secondary, tertiary structures and disulfide connectivity of $r C-N$

Secondary structure prediction and calculating the number of $\alpha$-helix, $\beta$-sheets, turns random coils, and extended strands of rC-N protein were carried out using Self-Optimized Prediction Method with Alignment (SOPMA) (http://npsa-pbil.ibcp.fr/cgibin/npsa_automat.pl?page=/NPSA/npsa_sopma.html) and Jpred (http://www.compbio.dundee.ac.uk/jpred/) tools $(19,20)$.

Disulfide connectivity of the $\mathrm{rC}-\mathrm{N}$ protein was analysed using DiAminoacid Neural Network Application (DiANNA) tool, which predicts cysteine conditions of proteins that have small number of disulfide bonds (21). To get informed of cys-cys connection is valu- able in perception the secondary and tertiary structure of protein, because it has an important role in fold permanence.

The Iterative Threading ASSEmbly Refinement (I-TASSER) online server program, which creates three dimensions (3D) models besides their confidence score (C-Score) was used in order to get tertiary structure prediction. $\mathrm{C}$-score is typically in the range of ( -5 to 2$)$, where a C-score of higher value signifies a model with a high confidence and vice-versa (22). Five top patterns were presaged and the best model among them was selected for structural analysis. The pattern was selected by three indicators: C-score, DFIRE2 energy profile (23) and stereo chemical qualities. Stereo chemical analysis of obtained 3D protein models was performed by PROCHECK, ERRAT, VERIFY 3D programs for structural analysis, which was authenticated by Structure Analysis and VErification Server (SAVES) (http://nihserver.mbi.ucla. edu/SAVES) and ramachandram plot assessment (RAM-PAGE) (mordred.bioc.cam.ac.uk/ rapper/rampage.php) (24-27).

\section{Prediction of T-cell epitopes from $r C-N$}

T-cell epitope regions of $\mathrm{rC}-\mathrm{N}$ were predicted using the web servers SYFPEITHI (http://www.syfpeithi.de/), ProPred-I (http:// www.imtech.res.in/raghava/propred1/) and IEDB (http://tools. iedb.org). The cut-off score was adjusted to $\geq 18$ for SYFPEITH $(28,29)$. The outcomes revealed a classified list of nine amino acid sub-strands of the proffered antigen sequence for affinity computations (30).

\section{Prediction of $r C-N$ antigenicity}

The antigenicity scores of all the predicted epitopes were examined by VaxiJen v2.0 online antigen prediction tool (http://www. ddg-pharmfac.net/vaxijen/). Epitopes having antigenic score $>0.5$ were selected as antigenic. VaxiJen v2.0 allows antigen assortment based on the physicochemical qualities of proteins without the use of sequence alignment (31).

\section{Cloning and expression of $r C-N$ protein}

The corresponding rC-N fragment (Core 1-118 aa, AAY linker and NS3, aa 1095-1387), was synthesised using Biomatik company (Canada) and was inserted into BamH I and EcoR I restriction sites of the pET24.a (+) vector, a T7 promoter based plasmid (Invitrogen, USA) and the recombinant construct was transformed into E. coli BL21-DE3 expression system (Invitrogen, USA). Then, induction was carried out with $1 \mathrm{mM}$ isopropyl B-D-thiogalactopyranoside (IPTG) (SinaClon bioscience Co, Iran) at $37{ }^{\circ} \mathrm{C}$ for 4 hours. Finally, lysate of bacteria expressing $\mathrm{rC}-\mathrm{N}$ protein was analysed using Poly Acrylamide Gel Electrophoresis on $12 \%$ sodium dodecyl sulfate (SDS-PAGE).

\section{Protein purification under native condition}

The recombinant $\mathrm{rC}-\mathrm{N}$ fusion was purified in native condition using Affinity chromatography method on a nickel-nitrilotriacetic acid (Ni-NTA)-agarose column (Qiagen, Germany) according to the manufacturer procedure. Briefly, the lysate of bacteria expressing $\mathrm{rC}-\mathrm{N}$ protein was solubilised by lysis buffer containing 2.5 $\mathrm{mM}$ imidazole and after 1 hour incubation on ice and sonication, 

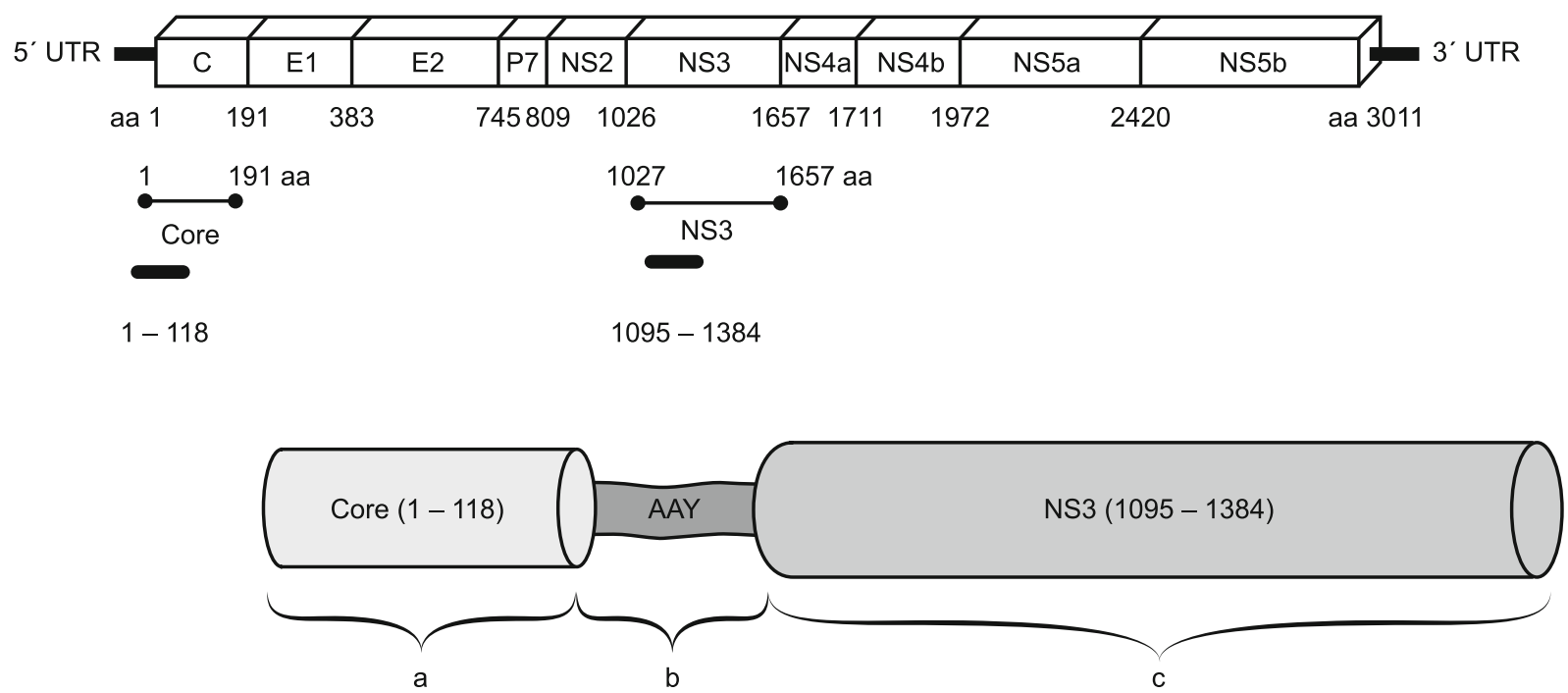

Fig. 1. (A) Schematic representation of the arrangement of core and NS3 in HCV full genome. (B) Recombinant Core-NS3 (rC-N) covering sequences from: a; The 1-118 amino acid parts of Core [Domain 1 (D1)], b; spacer. c; 1095-1384 amino acids of NS3.

the lysate was applied to the Ni-NTA column and following three times washing steps by washing buffer ( $50 \mathrm{mM}$ imidazole), the purified rC-N was eluted by elution buffer ( $250 \mathrm{mM}$ imidazole). To remove a high concentration of imidazole, evaluation sample was subsequently exchanged to PBS by overnight dialysis (cut off: 10 $\mathrm{KDa}$, Sigma, USA) at $4{ }^{\circ} \mathrm{C}$. and finally protein concentration was measured by Bradford method according to standard protocols.

\section{SDS-PAGE and Western blotting analysis}

The purified $\mathrm{rC}-\mathrm{N}$ protein was analysed by SDS-PAGE and western blotting. The bacterial pellets were suspended in a loading buffer, heated for 5 minutes at $95^{\circ} \mathrm{C}$, and $25 \mu \mathrm{L}$ of sample was subjected to $15 \%$ SDS-PAGE gel. Western blotting was used in order to verify the purified $\mathrm{rC}-\mathrm{N}$ protein. In this stage, after purification, the sample was separated by the SDS-PAGE and transferred on nitrocellulose membrane. The membrane was incubated with the conjugated His-tag antibody (Roche, Germany) for 1 hour at room temperature and developed by 3,3'- Diaminobenzidine (DAB) solution (Bio-Rad USA).

\section{Results}

Position of $r C-N$ in $H C V$ full genome and its arrangement

The schematic arrangement of the $\mathrm{rC}-\mathrm{N}$ protein (Domain 1 from Core, truncated middle region of NS3 that consists of some conserved parts of protease and helicase of NS3 and AAY linker between them) is indicated in Figure 1.

Physiochemical, Sequences and structural analysis of $r C-N$ protein

Physiochemical characterization of the $\mathrm{rC}-\mathrm{N}$ consisted of 437 amino acids with an estimated molecular weight of 46.7292 $\mathrm{kDa}$ and theoretical isoelectric point of 10.05 , with the calculated grand average hydropathicity of -0.392 , which indicates $\mathrm{rC}-\mathrm{N}$ is soluble and hydrophilic in nature. The total number of positively charged residues (Arg+ Lys) in the polypeptide was 51, and 27 of negatively charged residues (Asp+ Glu). The protein also contains 4 disulfide bridges (Tab. 1).

Secondary structure of the $\mathrm{rC}-\mathrm{N}$ protein showed that random coil makes the $55.61 \%$ of the protein while sheets, helices and turn contribute $24.71 \%, 11.67 \%$ and 8.01 of the structure, respectively (Fig. 2A).

Tertiary structure of the $\mathrm{rC}-\mathrm{N}$ protein was predicted using the I-TASSER online server and the best predicted structure with the maximum confidence score (C-Score:-1.57) was selected from a set of top models (Figs 2B and 2C).

\section{Prediction of T-cell epitopes}

T-cell epitope regions of $\mathrm{rC}-\mathrm{N}$ were predicted using the web servers SYFPEITHI (http://www.syfpeithi.de/), ProPred-I (http:// www.imtech.res.in/raghava/propred1/) and IEDB (http://tools. iedb.org). The cut-off score was adjusted to $\geq 18$ for SYFPEITH $(22,23)$. The outcomes revealed a classified list of nine amino acid sub-strands of the proffered antigen sequence for affinity computations (24).

Epitopes belonging to T cell epitopes were revealed on MHC I and MHCII. We used ProPred-I, IEDB and SYFPEITHI servers for the prediction of T-cell epitopes, with $3(\mathrm{H}-2 \mathrm{Kd}, \mathrm{H}-2 \mathrm{Dd}$ and $\mathrm{H}-2 \mathrm{Ld}$ ) alleles for MHC class I, and 2 (H2-IAd and H2-IEd) alleles

Tab. 1. Predicted disulfide bonds.

\begin{tabular}{lc}
\hline Position of Predicted bonds & Sequence of predicted bonds \\
\hline $105-168$ & YGNEGCGWAGW - RSLTPCTCGSS \\
$170-363$ & LTPCTCGSSDL - IICDECHSTDA \\
$216-360$ & GGPLLCPAGHA - YDIIICDECHS \\
$230-350$ & FRAAVCTRGVA - LADGGCSGGAY \\
\hline
\end{tabular}




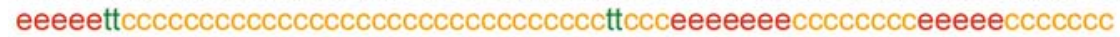
QPRGRRQPIPKARRPEGRTWAQPGYPWPLYGNEGCGWAGWLLSPRGSRPSWGPTDPRRRSRNLKLAAYMG

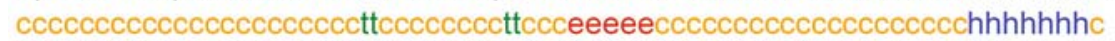
PVIQMYTNVDQDLVGWPAPQGARSLTPCTCGSSDLYLVTRHADVIPVRRRGDSRGSLLSPRPISYLKGSS chheeeecccttee ccccccccccccccccccccceeeeecccceeeeeccccccceeeccccceeetttt GGPLLCPAGHAVGIFRAAVCTRGVAKAVDFVPVENLETTMRSPVFTDNSSPPAVPQSFQVAHLQAPTGSG tcceeccttceeeeeehhechtthhhheeeccccchhhccccceecccccccccccceeeeeeccccccc KSTKVPAAYAAQGYKVLVLNPSVAATLGFGAYMSKAHGIDPNIRTGVRTITTGSPITYSTYGKFLADGGC cccccchhhhhttceeeeeccthhhhhcchhhhhhcttccttcceeeeeecccccceeeehceeeettcc SGGAYDIIICDECHSTDATSILGIGTVLDQAETAGARLVVLATATPPGSVTVPHPNIEEVALPPNGEIPF cccceeeeeeccccccccceeechhhhhhhhhhttceeeeeeccccttceeeccccceeeectttccce YGKAIPPLEEFHHHHHH Eeccoccchhhhhocccc

(A)

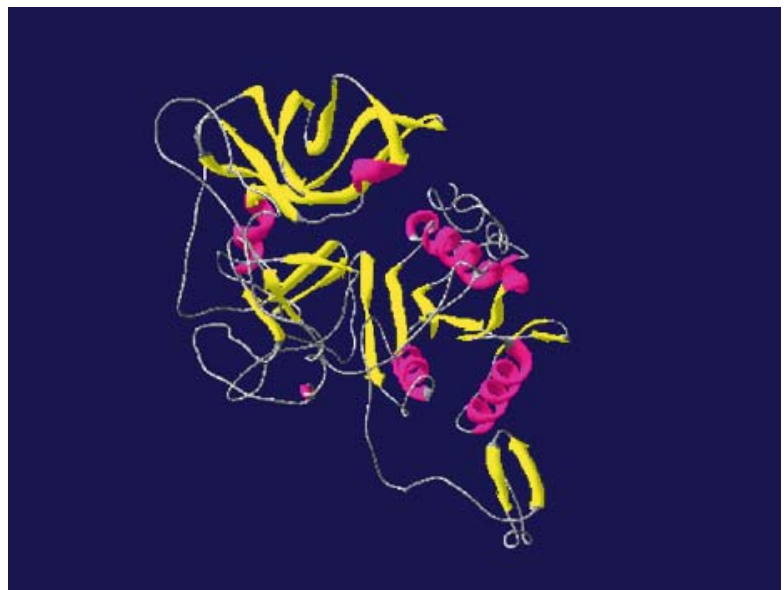

(B)

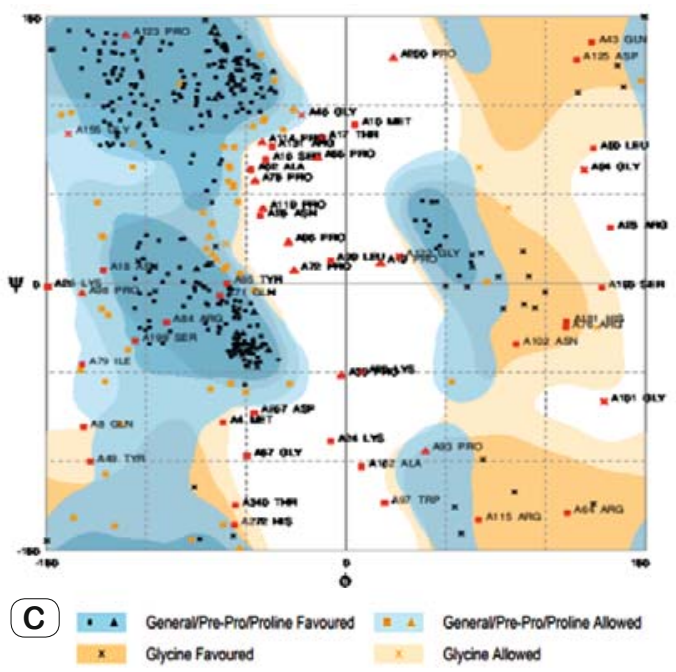

Fig. 2. Sequence and structural analysis of $\mathrm{rC}-\mathrm{N}$ protein. (A) Secondary structure of the protein with respect to protein sequence and (B) Predicted 3D model rC-N protein obtained from I-TASSER. Image was produced using the Swiss PDB viewer with colours identification as; helices, pink; beta sheets yellow; and all others grey. (C) Ramachandran plot is showing validation of protein structure using the phi and psi angles distribution in the protein. The Ramachandran plot shows that $74.9 \%$ of amino acid residues from modelled structure were incorporated in the favoured regions of the plot. Thirteen point one percentages of the residues were in allowed regions of the plot and $12.0 \%$ of residues in outlier regions.

for MHC class II. The epitopes with top score were predicted for MHC class I and II (Tabs 2 and 3). For MHC class I, 5 epitopes (FYGKAIPPL, HPNIEEVAL, RGPRLGVRA, PRGRRQPIP and LLPRRGPRL) showed antigenicity score greater than antigenicity threshold (0.5).

\section{Evaluation of the recombinant protein}

The $\mathrm{pET} 24 \mathrm{a}+$ expression vector harbouring $\mathrm{rC}-\mathrm{N}$ gene was confirmed using a restriction analysis (Fig. 3). Expression of fusion rC-N gene in E.coli BL21-DE3 resulted to a C-terminally 6x His-tagged protein that provided a simplified purification process. Evaluation of $\mathrm{rC}-\mathrm{N}$ protein using SDS-PAGE method indicated that the produced protein after IPTG induction was corresponding to $46.7292 \mathrm{kDa}$ fusion protein (Core 1-118 aa, AAY linker and NS3, aa 1095-1387). The homogenous protein band under native condition was purified and the protein size was determined about $47 \mathrm{KDa}$ in accordance to the calculated theoretical value by compute MW/pI tool (www.us.expasy.org) (Fig. 4).

\section{Discussion}

Current vaccines against HCV couldn't produce robust and broadly cross-reactive $\mathrm{CD} 4^{+}, \mathrm{CD} 8^{+} \mathrm{T}$-cells and neutralizing antibody (NAb) responses and couldn't prevent the virus completely. Therefore, as a realistic goal, a vaccine should prevent the progression of HCV infection to chronic and persistent infection by immunotherapy (32). Up to now, there isn't any licensed therapeutic vaccine against $\mathrm{HCV}$. With the improvement of bioinformatics, computational analysis and prediction of genomic and post-genomic structures of antigens became an applied approach in the first step 
Tab. 2. In silico analysis predicted MHC class I epitopes with 9 mer for $\mathrm{rC}-\mathrm{N}$ fusion protein.

\begin{tabular}{cccc}
\hline $\begin{array}{c}\text { Starting } \\
\text { position }\end{array}$ & Peptide & Allele & $\begin{array}{c}\text { Antigenicity } \\
\text { score }\end{array}$ \\
\hline $\mathbf{3 1 1}$ & AYMSKAHGI & $\mathbf{H}-2 \mathbf{K}^{\mathbf{d}}$ & $\mathbf{0 . 1 9 5 9}$ \\
$\mathbf{1 4 5}$ & MYTNVDQDL & $\mathbf{H}-2 \mathbf{K}^{\mathbf{d}}$ & $\mathbf{0 . 1 0 3 0}$ \\
$\mathbf{3 3 7}$ & TYSTYGKFL & $\mathbf{H}-2 \mathbf{K}^{\mathbf{d}}$ & $\mathbf{0 . 1 2 3 1}$ \\
420 & FYGKAIPPL & $\mathrm{H}-2 \mathrm{~K}^{\mathrm{d}}$ & 0.7316 \\
$\mathbf{4 1 2}$ & LPPNGEIPF & $\mathbf{H}-2 \mathbf{L}^{\mathbf{d}}$ & $\mathbf{0 . 3 5 1 4}$ \\
$\mathbf{2 6 0}$ & SPPAVPQSF & $\mathbf{H}-2 \mathbf{L}^{\mathbf{d}}$ & $\mathbf{0 . 3 5 2 3}$ \\
404 & HPNIEEVAL & $\mathrm{H}-2 \mathrm{~L}^{\mathrm{d}}$ & 1.1654 \\
$\mathbf{9 2}$ & QPGYPWPLY & $\mathbf{H}-2 \mathbf{L}^{\mathrm{d}}$ & $\mathbf{- 0 . 2 1 3 3}$ \\
50 & LLPRRGPRL & $\mathrm{H}-2 \mathrm{D}^{\mathrm{d}}$ & 0.6801 \\
$\mathbf{1 9 0}$ & RGDSRGSLL & $\mathbf{H}-2 \mathbf{D}^{\mathbf{d}}$ & $\mathbf{0 . 0 1 8 1}$ \\
54 & RGPRLGVRA & $\mathrm{H}-2 \mathrm{D}^{\mathrm{d}}$ & 1.2561 \\
$\mathbf{1 3 9}$ & MGPVIQMYT & $\mathbf{H}-2 \mathbf{D}^{\mathbf{d}}$ & $\mathbf{- 0 . 1 9 5 1}$ \\
72 & PRGRRQPIP & $\mathrm{H}-2 \mathrm{~K}^{\mathrm{d}}$ & 1.6553 \\
$\mathbf{4 2 5}$ & IPPLEEFHH & $\mathbf{H}-2 \mathbf{K}^{\mathbf{d}}$ & $\mathbf{0 . 0 7 8 9}$ \\
$\mathbf{1 7 5}$ & LYLVTRHAD & $\mathbf{H}-2 \mathbf{D}^{\mathbf{d}}$ & $\mathbf{0 . 4 9 3 2}$ \\
\hline
\end{tabular}

Non-Antigens are shown in bold face.

for vaccine design (33). Investigations showed the numerous in silico studies had examined the effects of various vaccines on pathogenic viruses, and indicated that the vaccines targets are mostly proteins (34). Therefore, in order to induce potent and firm immunological responses, specially cellular type, core and NS3 as two highly conserved immunogenic antigens of HCV with multi- specific $\mathrm{CD}^{+}$and $\mathrm{CD}^{+} \mathrm{T}$-cell responses were selected. These specifications make them attractive for peptide-based therapeutic vaccine design (35). But, full length of NS3 by protease and helicase enzymatic activities may disturb the APCs activities and reduce sufficient immune responses (36). Moreover, C- terminal domain of core is essential for processing of $\mathrm{HCV}$, and previous studies showed a suppression of immune response by full length of core in murine model $(37,38)$, and also, both terminals of core HCV have

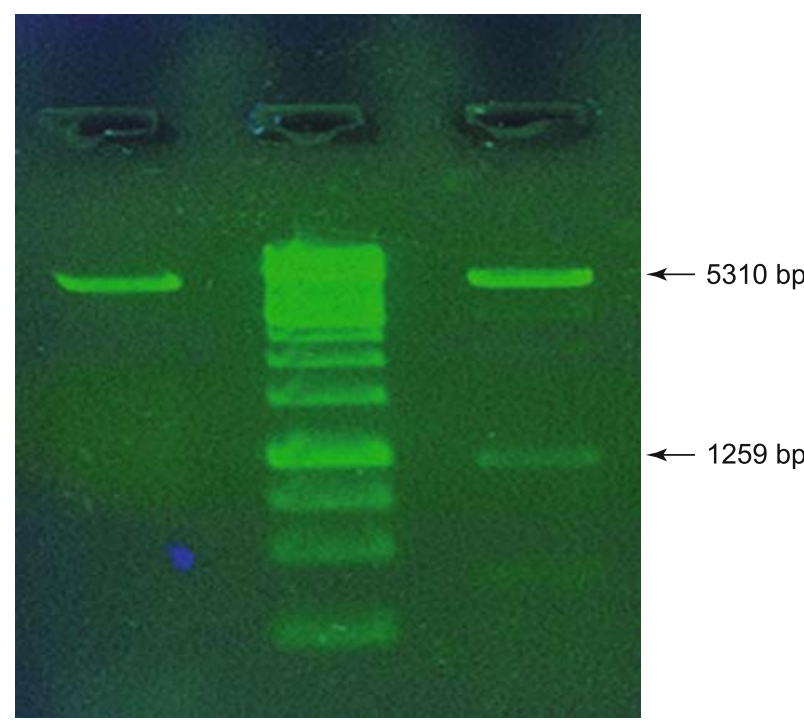

Fig. 3. Restriction analysis of the recombinant plasmid by $\mathrm{BamH}$ I and EcoR. Lane 1: undigested plasmid, Lane 2: DNA ladder marker (1Kb), Lane 3: The corresponding DNA fragment of digested recombinant plasmid (rC-N gene: 1259 bp and the vector: $5310 \mathrm{bp}$ ).
Tab. 3. In silico analysis predicted MHC class II epitopes with 15-mer, for $\mathrm{rC}-\mathrm{N}$ fusion protein.

\begin{tabular}{|c|c|c|c|}
\hline $\begin{array}{l}\text { Starting } \\
\text { position }\end{array}$ & Peptide & Allele & $\begin{array}{c}\text { Antigenicity } \\
\text { score }\end{array}$ \\
\hline 279 & SGKSTKVPAAYAAQG & $\mathrm{H} 2-\mathrm{IA}^{\mathrm{D}}$ & 0.6573 \\
\hline 291 & AQGYKVLVLNPSVAA & H2-IA ${ }^{\mathrm{D}}$ & 0.2886 \\
\hline 383 & TAGARLVVLATATPP & H2-IA ${ }^{\mathrm{D}}$ & 0.3801 \\
\hline 176 & YLVTRHADVIPVRRR & $\mathrm{H} 2-\mathrm{IA}^{\mathrm{D}}$ & 1.5777 \\
\hline 235 & AKAVDFVPVENLETTA & $\mathrm{H} 2-\mathrm{IA}^{\mathrm{D}}$ & 1.4968 \\
\hline 267 & SFQVAHLQAPTGSGK & $\mathrm{H} 2-\mathrm{IA}^{\mathrm{D}}$ & 0.6072 \\
\hline 282 & STKVPAAYAAQGYKV & H2-IA ${ }^{\mathrm{D}}$ & 0.3827 \\
\hline 378 & LDQAETAGARLVVLA & H2-IA ${ }^{\mathrm{D}}$ & 0.3252 \\
\hline 264 & VPQSFQVAHLQAPTG & $\mathrm{H} 2-\mathrm{IA}^{\mathrm{D}}$ & 0.4150 \\
\hline 280 & GKSTKVPAAYAAQGY & $\mathrm{H} 2-\mathrm{IA}^{\mathrm{D}}$ & 0.5660 \\
\hline 297 & LVLNPSVAATLGFGA & $\mathrm{H} 2-\mathrm{IA}^{\mathrm{D}}$ & 0.9593 \\
\hline 299 & LNPSVAATLGFGAYM & $\mathrm{H} 2-\mathrm{IA}^{\mathrm{D}}$ & 1.0267 \\
\hline 303 & VAATLGFGAYMSKAH & $\mathrm{H} 2-\mathrm{IA}^{\mathrm{D}}$ & 0.9851 \\
\hline 373 & GIGTVLDQAETAGAR & $\mathrm{H} 2-\mathrm{IA}^{\mathrm{D}}$ & 0.5933 \\
\hline 380 & QAETAGARLVVLATA & H2-IA ${ }^{\mathrm{D}}$ & 0.3065 \\
\hline 129 & RSRNLKLAAYMGPVI & $\mathrm{H} 2-\mathrm{IA}^{\mathrm{D}}$ & 0.9641 \\
\hline 256 & TDNSSPPAVPQSFQV & H2-IA ${ }^{\mathrm{D}}$ & 0.4598 \\
\hline 143 & IQMYTNVDQDLVGWP & H2-IA ${ }^{\mathrm{D}}$ & -0.3124 \\
\hline 207 & KGSSGGPLLCPAGHA & H2-IA ${ }^{\mathrm{D}}$ & -0.0795 \\
\hline 338 & YSTYGKFLADGGCSG & H2-IA ${ }^{\mathrm{D}}$ & 0.0147 \\
\hline 375 & GTVLDQAETAGARLV & H2-IA ${ }^{\mathrm{D}}$ & 0.3267 \\
\hline 388 & LVVLATATPPGSVTV & $\mathrm{H} 2-\mathrm{IA}^{\mathrm{D}}$ & 0.5535 \\
\hline 396 & PPGSVTVPHPNIEEV & $\mathrm{H} 2-\mathrm{IA}^{\mathrm{D}}$ & 0.5115 \\
\hline 95 & YPWPLYGNEGCGWAG & $\mathrm{H} 2-\mathrm{IA}^{\mathrm{D}}$ & 0.5449 \\
\hline 33 & PQDVKFPGGGQIVGG & $\mathrm{H} 2-\mathrm{IA}^{\mathrm{D}}$ & -0.0265 \\
\hline 118 & RPSWGPTDPRRRSRN & $\mathrm{H} 2-\mathrm{IE}^{\mathrm{D}}$ & 1.7912 \\
\hline 311 & AYMSKAHGIDPNIRT & $\mathrm{H} 2-\mathrm{IE}^{\mathrm{D}}$ & 0.6769 \\
\hline 92 & QPGYPWPLYGNEGCG & H2-IE ${ }^{\mathrm{D}}$ & -0.0432 \\
\hline 21 & PQRKTKRNTNRRPQD & H2-IE & 0.1123 \\
\hline 47 & GVYLLPRRGPRLGVR & $\mathrm{H} 2-\mathrm{IE}^{\mathrm{D}}$ & 1.2585 \\
\hline 179 & TRHADVIPVRRRGDS & $\mathrm{H} 2-\mathrm{IE}^{\mathrm{D}}$ & 1.3969 \\
\hline 226 & RAAVCTRGVAKAVDF & $\mathrm{H} 2-\mathrm{IE}^{\mathrm{D}}$ & 0.7941 \\
\hline 55 & GPRLGVRATRKTSER & $\mathrm{H} 2-\mathrm{IE}^{\mathrm{D}}$ & 1.3117 \\
\hline 73 & RGRRQPIPKARRPEG & H2-IE ${ }^{\mathrm{D}}$ & 0.1051 \\
\hline 104 & GCGWAGWLLSPRGSR & $\mathrm{H} 2-\mathrm{IE}^{\mathrm{D}}$ & 0.6286 \\
\hline 153 & LVGWPAPQGARSLTP & $\mathrm{H} 2-\mathrm{IE}^{\mathrm{D}}$ & 0.7407 \\
\hline 184 & VIPVRRRGDSRGSLL & H2-IE ${ }^{\text {D }}$ & 0.4811 \\
\hline 43 & QIVGGVYLLPRRGPR & $\mathrm{H} 2-\mathrm{IE}^{\mathrm{D}}$ & 0.5810 \\
\hline 46 & GGVYLLPRRGPRLGV & $\mathrm{H} 2-\mathrm{IE}^{\mathrm{D}}$ & 0.8929 \\
\hline 107 & WAGWLLSPRGSRPSW & $\mathrm{H} 2-\mathrm{IE}^{\mathrm{D}}$ & 0.6516 \\
\hline 222 & VGIFRAAVCTRGVAK & H2-IE & -0.6039 \\
\hline 417 & EIPFYGKAIPPLEEF & H2-IE ${ }^{\text {D }}$ & 0.4868 \\
\hline 13 & GSMSTNPKPQRKTKR & $\mathrm{H} 2-\mathrm{IE}^{\mathrm{D}}$ & 1.0111 \\
\hline 16 & STNPKPQRKTKRNTN & $\mathrm{H} 2-\mathrm{IE}^{\mathrm{D}}$ & 0.9401 \\
\hline 145 & MYTNVDQDLVGWPAP & H2-IE ${ }^{\text {D }}$ & -0.1459 \\
\hline
\end{tabular}

autoimmune sequences that are deleterious for vaccine activity (39). Then we used the middle region of NS3, containing some parts of helicase and protease of NS3 and first domain of core without $\mathrm{C}$ terminus of core in order to design and construct a recombinant fusion protein as an efficient candidate for $\mathrm{HCV}$ therapeutic vaccine.

Herein, in silico analysis was applied in computational biotechnology for rational verification and designing of $\mathrm{rC}-\mathrm{N}$ protein for $\mathrm{HCV}$ vaccine development. Accordingly, a new fused construct of hepatitis C peptides including core (1-118) and NS3 (1095-1384) was designed, constructed, expressed and purified as an antigen. A protease-sensitive linker (AAY) was placed between them, in order to optimize the site of fission to facilitate the processing of this bipartite fusion protein and decrease altered bioactivity of the 
189-195

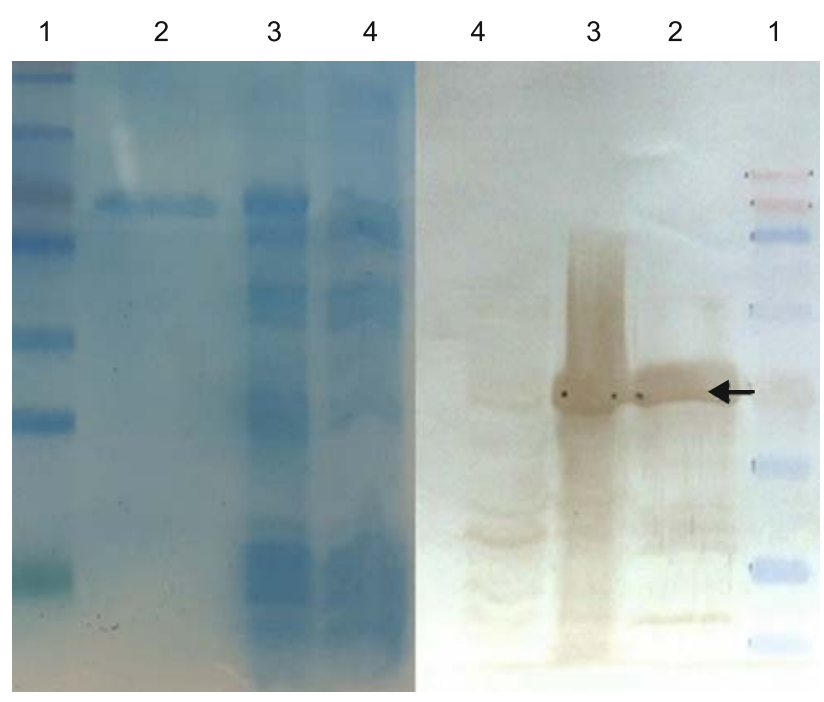

Fig. 4. The profile of rC-N fusion protein by A: SDS PAGE and B: Western blotting for confirmation of expression and purification. Lane1: Pre-stained Protein ladder (9-170 kDa). Lane 2: purified rC-N (46.7292 kDa band indicated by arrow in fig B). Lane 3: Induced lysate by IPTG. lane 4: Uninduced lysate.

protein moieties by the juxtaposition of the epitopes (40). This protein has four disulfide bridges (Table 1), which render extracellular stability in its structure. Ramachandran plot analysis through RAMPAGE of the predicted model resulted in the favoured region and showed that most of the residues are in the allowed regions of the plot, then proving validity of the model.

The I-TASSER online server was used to provide the most accurate structure. The C-Score is an evaluation of the statue of the predicted models by I-TASSER and is calculated based on the importance of threading template alignments and the proximity parameters of the structure assembly reproductions (21). The value of C-score was in the acceptable confidence $(-1.57)$.

The MHC class I presented by target cells along with MHC class II epitopes presented by APCs with antigenic value up to threshold and conservancy predicted in this chimeric protein. Pursuant to aforementioned predictions and results, $\mathrm{rC}-\mathrm{N}$ has antigenic behaviour to create $\mathrm{CD} 4+, \mathrm{CD} 8+\mathrm{T}$ cell responses. The present fusion protein is a scaffold for therapeutic vaccine. This study showed the capability of the $\mathrm{rC}-\mathrm{N}$ in virtual environment, but it will be challenged in solitude or with different adjuvants in vivo to improve immune responses in BALB/c mice, with regard to further evaluation to produce firstly an effective cellular, and or humoral immunity.

\section{References}

1. Messina JP, Humphreys I, Flaxman A, Brown A, Cooke GS, Pybus OG et al. Global Distribution and Prevalence of Hepatitis C Virus Genotypes. Hepatology 2015; 61 (1): 77-87.

2. Mohd Hanafiah K, Groeger J, Flaxman AD, Wiersma ST. Global epidemiology of hepatitis $C$ virus infection: new estimates of age-specific antibody to HCV seroprevalence. Hepatology 2013; 57 (4): 1333-1342.
3. Majumdar A, Kitson MT, Roberts SK. Systematic review: current concepts and challenges for the direct-acting antiviral era in hepatitis $\mathrm{C}$ cirrhosis. Aliment Pharmacol Ther 2016; 43 (12): 1276-1292.

4. Barth H. Hepatitis C virus: Is it time to say goodbye yet? Perspectives and challenges for the next decade. World J Hepatol 2015; 18; 7 (5): 725-737.

5. Kato N. Genome of human hepatitis C virus (HCV): gene organization, sequence diversity, and variation. Microb Comp Genomics 2000; 5 (3): 129-151.

6. Dubuisson J. Hepatitis C virus proteins. World J Gastroenterol 2007; 13 (17): 2406-2415.

7. Ashfaq AU, Javed T, Rehman S, Nawaz Z, Riazuddin S. An overview of HCV molecular biology, replication and immune responses. Virol J 2011; 8 (4): 161.

8. Moradpour D, Penin F. Hepatitis C Virus Proteins: From Structure to Function. Curr Top Microbiol Immunol 2013; 369: 113-142.

9. Bukh J, Purcell RH, Miller RH. Sequence analysis of the core gene of 14 hepatitis C virus genotypes. Proc Natl Acad Sci 1994; 91: 8239-8243.

10. Saeedi A, Ghaemi A, Tabarraei A, Moradi A, Gorji A, Semnani S et al. Enhanced cell immune responses to hepatitis $\mathrm{C}$ virus core by novel heterologous DNA prime/lambda nanoparticles boost in mice. Virus Genes 2014; 49 (1): 11-21.

11. Morikawa K, Lange CM, Gouttenoire J, Meylan E, Brass V, Penin F, Moradpour D. Nonstructural protein 3-4A: the Swiss army knife of hepatitis C virus. J Viral Hepat 2011; 18 (5): 305-315.

12. Nascimento IP, Leite LCC. Recombinant vaccines and the development of new vaccine strategies. Braz J Med Biol Res 2012; 45 (12): 1102-1111.

13. Shi C, Ploss A. Hepatitis C Virus Vaccines in the Era of New Directacting Antivirals. Expert Rev Gastroenterol Hepatol 2013; 7 (2): 171-185.

14. Ward S, Lauer G, Isba R, Walker B, Klenerman P. Cellular immune responses against hepatitis $C$ virus: the evidence base 2002. Clin Exp Immunol 2002; 128 (2): 195-203.

15. Neumann-Haefelin C, Thimme R. Success and failure of virus-specific T cell responses in hepatitis C virus infection. Dig Dis 2011; 29 (4): 416-422.

16. Thimme R, Oldach D, Chang KM, Steiger C, Ray SC, Chisari FV. Determinants of viral clearance and persistence during acute hepatitis C virus infection. J Exp Med 2001; 194 (10): 1395- 1406.

17. Hosseini SY, Sabahi F, Moazzeni SM, Modarressi MH, Saberi Firoozi M, Ravanshad M. Construction and preparation of three recombinant adenoviruses expressing truncated NS3 and core genes of hepatitis C virus for vaccine purposes. Hepat Mon 2012; 12 (8): e6130.

18. Wilkins MR, Gasteiger E, Bairoch A, Sanchez JC, Williams KL, Appel RD et al. Protein identification and analysis tools in the ExPASy server. Methods Mol Biol 1999; 112: 531-552.

19. Cuff JA, Clamp M E, Siddiqui AS, Finlay M, Barton GJ. Jpred: a consensus secondary structure prediction server. Bioinformatics 1998; 14 (10): 892-893.

20. Geourjon C, Deleage G. SOPMA: significant improvements in protein secondary structure prediction by consensus prediction from multiple alignments. Comput Appl Biosci 1995; 11 (6): 681-684.

21. Ferrè F, Clote P. DiANNA: a web server for disulfide connectivity prediction. Nucleic Acids Res 2005; 33 (Web Server issue): W230-232. 
22. Zhang Y. I-TASSER server for protein 3D structure prediction. BMC Bioinformatics 2008; 9 (40): 1-8.

23. Yang Y, Zhou Y. Specific interactions for ab initio folding of protein terminal regions with secondary structures. Proteins 2008; 72 (2): 793-803

24. Laskowski RA, MacArthur MW, Moss DS, Thornton JM. PROCHECK -a program to check the stereochemical quality of protein structures. J App Cryst 1993; 26 (2): 283-291.

25. Colovos C, Yeates TO. Verification of protein structures: patterns of non-bonded atomic interactions. Protein Sci 1993; 2 (9): 1511-1519.

26. Bowie JU, Luthy R, Eisenberg D. A method to identify protein sequences that fold into a known three-dimensional structure. Science 1991; 253 (5016): 164-170.

27. Lovell SC, Davis IW, Arendall WB , de Bakker PIW, Word JM, Prisant MG et al. Structure validation by C-alpha geometry, phi, psi and $\mathrm{C}$ beta deviation. Proteins 2003; 50 (3): 437-450.

28. Rammensee H, Bachmann J, Emmerich NP, Bachor OA, Stevanovic S. SYFPEITHI: database for MHC ligands and peptide motifs. Immunogenetics 1999; 50 (3-4): 213-219.

29. Singh H, Raghava GPS. ProPred1: Prediction of promiscuous MHC class-I binding sites. Bioinformatics 2003; 19 (8): 1009-1014.

30. Peters B, Sidney J, Bourne P, Bui HH, Buus S, Doh G et al. The immune epitope database and analysis resource: from vision to blueprint. PLoS Biol 2005; 3 (3): e91.

31. Doytchinova IA1, Flower DR. VaxiJen: a server for prediction of protective antigens, tumour antigens and subunit vaccines. BMC Bioinformatics 2007; 8: 4.
32. Xue J, Zhu H, Chen Z. Therapeutic vaccines against hepatitis $C$ virus. Infect Genet Evol 2014; 22: 120-129.

33. Kanampalliwar AM, Soni R, Girdhar A, Tiwari A. Reverse Vaccinology: Basics and Applications. J Vaccines Vaccin 2013; 4 (6): 1-5.

34. He Y, Rappuoli R, De Groot AS, Chen RT. Emerging Vaccine Informatics. J Biomed Biotechnol 2010; 2010: 218590.

35. Encke J, zu Putlitz J, Geissler M, Wands JR. Genetic immunization generates cellular and humoral immune responses against the nonstructural proteins of the hepatitis $\mathrm{C}$ virus in a murine model. J Immunol 1998; 161 (9): 4917-4923.

36. Haller AA, Lauer GM, King TH, Kemmler C, Fiolkoski V, Lua Y et al. Whole recombinant yeast-based immunotherapy induces potent $\mathrm{T}$ cell responses targeting HCV NS3 and core proteins. Vaccine 2007; 25 (8): 1452-1463.

37. Large MK, Kittlesen DJ, Hahn YS. Suppression of host immune response by the core protein of hepatitis $\mathrm{C}$ virus: Possible implications for hepatitis C virus persistence. J Immunol 1999; 162: 931-938.

38. Alverez-Obrego'n JCs, Duen as-Carrera S, Valenzuela C, Grollo JM. A truncated HCV core strong participation of cellular immunity components in mice. Vaccine 2001; 19 (28-29): 3940-3946.

39. Lui Y, Zhou W, You C, Zheng H, Lui H, Zheng D et al. An autoimmune domain-reduced $\mathrm{HCV}$ core gene remains effective in stimulating anticore ctotoxic T lymphocyte activity. Vaccine 2006; 24 (10): 1615-1624.

40. Guan, X, Zou J, Gu H, Yao Z. Short amyloid-[beta] immunogens with spacer-enhanced immunogenicity without junctional epitopes for Alzheimer's disease immunotherapy. Neuroreport 2012; 23 (15): 879-884.

Received December 21, 2016. Accepted January 11, 2017. 